\title{
Biodiversity recovery during rainforest reforestation as indicated by rapid assessment of epigaeic ants in tropical and subtropical Australia
}

\author{
Scott D. Piper ${ }^{1 \dagger}$, Carla P. Catterall ${ }^{1}$, John J. Kanowski ${ }^{1 *}$, and Heather C. Proctor ${ }^{1,2}$ \\ ${ }^{1}$ School of Environment, Griffith University, Nathan, Queensland 4111, Australia. \\ ${ }^{2}$ Present address: Department of Biological Sciences, University of Alberta, Edmonton, \\ Alberta T6G 2E9, Canada \\ * Corresponding author \\ ${ }^{\dagger}$ Deceased \\ Email: J.Kanowski@griffith.edu.au
}

Phone: (07) 37353823

Fax: (07) 37354209

Suggested running title: Ant genera and rainforest restoration 


\section{ABSTRACT}

There is growing interest in the potential for reforestation to assist the recovery of rainforest biodiversity. There is also a need to identify taxonomically-tractable groups for use as cost-effective indicators when monitoring the status of biodiversity within reforested sites. Insects are an important component of terrestrial biodiversity but often require considerable resources to sample at species level. Ant genera and generic-based functional groups have been suggested as possible indicators of environmental disturbance. Here we ask to what extent the development of biodiversity is indicated by epigeic ant genera and functional groups, across different types of reforestation in tropical and subtropical Australia. In each region, we used pitfall traps to sample the ants in replicate sites of: unmanaged regrowth; monoculture and mixed species plantations; and 'ecological restoration' plantings; together with reference sites in pasture and rainforest. We recorded 35 epigaeic ant genera (and 4,623 individuals) from 50 tropical sites, and 39 genera (and 9,904 individuals) from 54 subtropical sites, with 47 genera overall. Community composition of both genera and functional groups differed between pasture and rainforest, although many genera were widespread in both. Reforested sites were intermediate between pasture and rainforest in both regions, and showed a gradient associated with decreasing grass and increasing tree and litter cover. Older monoculture plantations and ecological restoration plantings had the most rainforest-like ant assemblages, and mixed-species cabinet timber plots the least, of the reforested sites. We conclude that ground-active ant genera and functional groups sampled in rapid surveys by pitfall-trapping showed only a modest ability to discriminate among different types of reforestation. Species-level identification, perhaps 
together with expanded sampling effort, could be more informative, but would require resourcing beyond the scope of rapid assessments.

Keywords: bioindicators, ecological restoration, Formicidae, revegetation, functional group

\section{INTRODUCTION}

Following the recognition that clearing of tropical rainforests has caused substantial biodiversity decline world wide, there is a growing interest in the potential for reforestation to assist the recovery of biodiversity (Chazdon 2003; Lamb et al. 2005). There are many alternative pathways through which forests may return to cleared land, including various types of timber plantations, restoration plantings and regrowth, and these differ in establishment costs, landholder motivations, floristic diversity, physical structure and rates of vegetation development (Ashton et al. 2001; Catterall et al. 2004; Lamb et al. 2005). There is a need to measure and monitor the extent to which these various 'emerging' or 'new' forests (Lugo \& Helmer 2004) are able to support or rescue the biota which previously depended on remnants of indigenous forest, so that the processes of recovery can be better understood, and the design and management of these forests can be progressively improved (Catterall et al. 2008). There is also an emerging need to assess the return on investment in biodiversity recovery (Freudenberger \& Harvey 2003).

The issue of exactly what should be monitored in order to provide the most useful and cost-effective information about biodiversity development during reforestation is, however, contentious. There is unresolved debate about issues such as the validity of assumptions concerning ecological surrogacy, the level of taxonomic resolution 
required to detect environmental change, the determination of appropriate performance criteria, and the allocation of sampling effort within versus between sites (Brown 1997; Williams \& Gaston 1994; McGeogh 1998; Lindenmayer et al. 1999; Pik et al. 1999; Catterall et al. 2004; Kanowski et al. 2008).

The monitoring of revegetation is often focused on the survival, growth and recruitment of plants and the use of revegetated sites by vertebrate animals (see, e.g., Parrotta et al. 1997; Block et al. 2001). Invertebrates are an important component of terrestrial ecosystems (Wilson 1990; Folgarait 1998), and therefore need to be included in biodiversity assessments. However, assessing their response to environmental changes presents several problems. Sorting invertebrate samples to species requires large investments of time and taxonomic expertise, a particular problem in the tropics, where many species are undescribed and lack identification keys (Lawton et al. 1998; Krell 2004). Furthermore, the occurrence of invertebrate species can be very variable in space or time, making it difficult to detect the effects of environmental factors on patterns of species distribution (Wilson 1958; Kaspari 2000; New 2000; Grimbacher et al. 2008).

Using supra-species (e.g., genus or family) levels of classification avoids some of these time and expertise constraints and may also reduce the variability between samples. Studies based on sorting to higher taxa have, in a number of cases, provided meaningful information on assemblage responses to environmental change (Williams \& Gaston 1994; Balmford et al. 1996; Bailey et al. 2001; Cagnolo et al. 2002; Nakamura et al. 2003; Pik et al. 2002; Schnell et al. 2003; Kitching et al. 2004; Grimbacher et. al. 2008). This leads to trade-offs between rapid assessment and taxonomic resolution in 
monitoring studies (Gaston \& Williams 1993; McGeogh 1998; Neville \& New 1999; Ward \& Lariviere 2004).

Ants (Hymenoptera: Formicidae) have been widely used as indicators of recovery from environmental disturbance, especially within Australia (Majer 1983; Andersen 1990; Hoffman \& Andersen 2003; Andersen \& Majer 2004; Nakamura et al. 2003, 2007, 2008). Ant genera are clearly defined and described in many regions (Andersen 1995a). However, identifying ants to species is difficult for non-specialists, and many species remain undescribed, especially in high-diversity tropical areas (Brown 2000; Longino et al. 2002). Some studies using ants have found strong parallels between species- and genus-level patterns of diversity and multivariate assemblage similarity amongst sites (Andersen 1995a; Major et al. 1999; Pik et al. 1999; Neville \& New 1999; Pik et al. 2002; Schnell et al. 2003).

The use of functional groupings, based largely on genus-level identification, has been proposed and applied as a cost-effective means of detecting the response of ant assemblages to environmental change (Andersen 1995b, 1997, 2000; Brown 2000; Hoffman \& Andersen 2003). Many studies using ants as environmental indicators have surveyed assemblages of ground-active ants using pitfall traps, a sampling technique which can readily be incorporated as a standard methodology within broader biodiversity surveys.

However, much of this work has taken place in relatively open habitats such as sclerophyll forest, woodland and semi-arid environments. It is not clear whether the rapid assessment of epigaeic ant assemblages at genus level is likely to be equally useful in studies of ecological disturbance and recovery in rainforest landscapes. Nakamura et al. (2003) found that ant genera did not discriminate well between restored 
rainforest of different ages in subtropical eastern Australia. In contrast, King et al. (1998) claimed a high utility of ant functional groups for assessing rainforest restoration in tropical eastern Australia, although this conclusion was speculative given their low replication of survey sites. More generally, it has been suggested that assessments based on functional groups may be especially useful in mesic forested habitats, where deforestation would have large microclimatic effects (Hoffman \& Andersen 2003).

However, there are also reasons for expecting that ant genera and functional groups may be less useful for rapid ecological assessments of rainforest landscapes than in drier environments. First, many of the ant genera that characterise undisturbed rainforest are intrinsically uncommon or patchy (Wilson 1958; Soares \& Schoereder 2001; Nakamura et al. 2007), and therefore unlikely to reveal statistically significant patterns without very intensive sampling. Second, the common thermophilic ant genera such as Iridomyrmex, which help give predictive power to the functional group approach (Andersen 1995b), are likely to be scarce in rainforest landscapes (see for example Nakamura et al. 2007), and where present they may avoid the shaded soil of denselygrassed pasture.

Given these uncertainties, the present study was designed to assess the extent to which biodiversity variation arising from different forms of reforestation within rainforest landscapes was revealed by rapid assessment of pitfall-trapped ant assemblages considered at the levels of genus and functional group. The study used two spatially-dispersed landscape-scale networks of sites, in the Australian tropics and subtropics, with each network containing five different types of reforestation and two reference conditions (rainforest, pasture). Since the reforested sites were selected to provide contrasting states of vegetation structure and tree species diversity (Kanowski et 
al. 2003; Wardell-Johnson et al. 2005), we expected that many taxa should show variation in frequency among them. Variation in composition of other faunal taxa at these same sites has been described by Catterall et al. (2004), Kanowski et al. (2005, 2006) and Grimbacher et al. (2007).

\section{METHODS}

\section{Study context and design}

The present study was part of a broader project that had the goal of quantifying the biodiversity value of reforestation in former rainforest landscapes, through the assessment of a range of taxa, processes and structural attributes at a common array of sites (Catterall et al. 2004). Fieldwork was carried out in two regions of eastern Australia: the Atherton Tablelands in tropical north Queensland $\left(17^{\circ}-17^{\circ} 30^{\prime} \mathrm{S}, 145^{\circ} 30\right.$ $-145^{\circ} 45 \mathrm{E} ; 500-850 \mathrm{~m}$ a.s.1.; annual rainfall $1300-3000 \mathrm{~mm}$ ); and the lowlands of subtropical south east Queensland and northern New South Wales $\left(26^{\circ} 30^{\prime}-29^{\circ} \mathrm{S}\right.$, $152^{\circ} 30^{\prime}-153^{\circ} 30 \mathrm{E} ; 10-400 \mathrm{~m}$ a.s.1; rainfall $\left.1100-2000 \mathrm{~mm}\right)$. Within these regions, large tracts of rainforest have been cleared, mainly for the establishment of pasture (Adam 1994). Recently, numerous reforestation attempts have commenced, ranging from the planting of monoculture or multi-species cabinet timber plots, to 'ecological restoration' schemes which attempt to recreate more faithfully the original vegetation associated with a site (Catterall et al. 2004; Erskine et al. 2007). Large areas of cleared land have also developed a cover of unmanaged regrowth, often dominated by exotic plants, following abandonment of agricultural land (Neilan et al. 2006; Erskine et al. 2007). 
Within each region, 5-10 independent replicate sites were selected within each of two reference states and five reforestation treatments. The reference states were pasture $(\mathrm{P}$; $\mathrm{n}=5$ in each region) on land that formerly carried rainforest, and mature rainforest $(\mathrm{F}$; $\mathrm{n}=10$ in each region), matched as closely as possible for environmental conditions with reforested sites. The five reforestation treatments, selected to typify approaches used in eastern Australia (Catterall et al. 2004), were: (1) patches of unmanaged regrowth (RG; $\mathrm{n}=5$ in each region), 30-40 years old in the subtropics and dominated by introduced camphor laurel Cinnamomum camphora or privet Ligustrum spp., and 10-20 years old in the tropics and dominated by a mixture of grasses, shrubs and scramblers; (2) young (5-10 years) mixed-species cabinet timber plantations $(\mathrm{CT} ; \mathrm{n}=10$ in the subtropics, $\mathrm{n}=5$ in the tropics), which typically included a mix of rainforest and eucalypt species; $(3,4)$ monoculture timber plantations (mostly stands of Araucaria) in each of two age classes, young $(5-15$ years $)(Y P ; n=5$ in each region $)$ and old $(38-70$ years $)(\mathrm{OP} ; n=10$ in each region); and (5) 'ecological restoration' plantings (ER; $n=9$ in the subtropics, $n=10$ in the tropics), which were 6-22 years old and had a diverse mix of trees and shrubs planted at relatively high densities. RG, CT and ER sites had been established on land which had previously been pasture. OP sites had been established immediately after clearing of the original rainforest. YP sites were second-rotation plantations, with the exception of a single YP site in each region that had been established on pasture. Further details of the study design are provided elsewhere (Kanowski et al. 2003; Catterall et al. 2004). Within each region, sites were widely dispersed, over an area of more than $500 \mathrm{~km}^{2}$, and different site-types were interspersed as far as possible, subject to constraints arising from non-random land use patterns. Replicate sites in each treatment were generally $1-10 \mathrm{~km}$ apart, except for monoculture plantations, where 
sites were restricted to a few localities in each region, and some were a few hundred metres apart.

\section{Sampling}

A $90 \mathrm{~m}$ transect was established at each site. To survey ground-active invertebrates, 10 pitfall traps, each $5 \mathrm{~cm}$ in diameter, were deployed at $10 \mathrm{~m}$ intervals along the transect, during March 2001 (subtropics) and April-May 2001 (tropics). Traps were partly-filled with dilute methylated spirits, to which a drop of detergent was added. The tops of the traps were flush to the ground, and a few twigs were placed over them, as well as an inverted petri dish 1-2 $\mathrm{cm}$ above ground to protect them from rain. Traps were exposed for three days and nights. Although longer trap exposure times may have resulted in a more comprehensive sample of the local ant fauna, survey periods of 2-5 days are commonly employed in assessments of epigeic ant fauna (e.g., Andersen 1995b, 1997; King et al. 1998; Agosti \& Alonso 2000; Andersen et al. 2002). Sampling periods were temporally interspersed among site-types to control for any variation in capture success due to weather or other factors.

Initial taxonomic identification was provided by BioTrack Australia Pty Ltd (Macquarie University, Sydney), with subsequent reassignments of some specimens by Chris Burwell and Aki Nakamura (Queensland Museum and Griffith University). The reference collection is stored at Griffith University. The taxonomic nomenclature used here is consistent with Shattuck and Barnett (2001). We grouped genera into the functional groups described by Andersen (1995b), or using Brown (2000) where necessary. The functional groups were Dominant Dolichoderinae, Generalised Myrmicinae, Opportunists, Subordinate Camponotini, Cryptic Species, Specialist Predators, and Climate Specialists, which were further separated into Hot Climate 
Specialists, Cold Climate Specialists, and Tropical Climate Specialists. Genera that encompassed species from more than one functional group were excluded from the functional group analysis. However, we were able to place $98 \%$ of individuals overall, and no fewer than $92 \%$ of individuals in any particular site, into a functional group.

A number of variables relating to vegetation structure were also measured within five subplots at each site, and then pooled or averaged to obtain a single site measure (Kanowski et al. 2003). Four key variables related to vegetation development were considered in the current paper: canopy foliage cover $(\%)$, tree basal area $\left(\mathrm{m}^{2} / \mathrm{ha}\right)$, litter dry weight ( $\mathrm{t} / \mathrm{ha}$ ), and groundcover of grasses (index, 0-25).

\section{Statistical analysis}

A separate set of analyses was carried out for each region. Because the abundance of ants trapped by any pitfall may be strongly affected by chance proximity to nests and foraging trails, capture data are often transformed at the scale of individual traps to reduce distortion of summary counts (Andersen 1990; Hoffmann \& Andersen 2003). In much of the literature on ant functional groups, trap-level abundance data are transformed to a six-point ordinal scale (e.g. $1=1$ ant, $2=2-5$ ants, $3=6-10$ ants, etc: see Andersen 1997), although $\ln (\mathrm{x}+1)$ transformations (Hoffmann \& Andersen 2003) and presence/ absence transformations (Andersen et al. 2002) at the site scale have been used in some cases. In the present paper, we transformed trap-level data to presence/ absence, and used the number of pitfall traps (out of 10) at each site in which each genus was recorded as our measure of relative abundance (hereafter 'frequency') in all analyses. Preliminary analyses showed that these frequencies were highly correlated with relative abundances based on the six-point ordinal scale of Andersen (1997), with $P<0.001$ for all tests. These tests were Pearson correlations across sites within each 
region (subtropics $n=54$ sites, tropics $n=50$ sites), for each genus recorded at more than five sites in the region (15 subtropical genera, 11 tropical genera), as well as Mantel correlations (based on Bray-Curtis distances) for the multivariate data set in each region.

Ant genera potentially indicative of pasture or rainforest conditions were identified using the IndVal procedure (Dufrene \& Legendre 1997) using data from the pasture and rainforest reference sites only. Each IndVal measure (range 0-100\%, for each tested genus, with respect to each habitat) combined the frequency and consistency of occurrence within-habitat (rainforest or pasture) with the extent of avoidance of the other habitat, with statistical significance determined by a randomisation procedure. For each significant rainforest or pasture 'indicator' genus, variation in frequency across all site-types was then tested using Analysis of Variance (ANOVA) together with post-hoc pairwise LSD tests, based on log-transformed frequencies. ANOVA $P$ values were determined by randomisation, to improve the robustness of the results to variation in the datasets (Edgington 1980). Randomisations were performed with 1,000 iterations using the programs PopTools (Hood 2007) and Resampling Stats in Excel (Blank et al. 2001).

Ant functional groups are typically evaluated in terms of their proportional abundance at a site (Hoffman \& Andersen 2003). Hence, for functional group analyses, frequency values were summed across member genera for each functional group, and then converted to proportional frequencies within each site by dividing each functional group's summed frequency by the total frequency of all functional groups. The occurrence of selected groups (Dominant Dolichoderinae, Generalised Myrmicinae, Opportunists, Specialist Predators and Cryptic Species) was compared among site-types with randomisation-based ANOVAs of arcsine-transformed proportional frequencies. 
The selected groups comprised most of the captured taxa, and were those expected to show a response to disturbance (Hoffman \& Andersen 2003).

The patterns of among-site variation in genus and functional group composition were visualised using non-metric multidimensional scaling (MDS) ordinations for each region, based on the Bray-Curtis distance measure. The statistical significance of multivariate differences among site-types was tested with Analysis of Similarity (ANOSIM: Clarke \& Green 1988). These analyses used the software package PRIMER (Clarke \& Warwick 2001). The relationships between vegetation structure and ant assemblage composition were assessed by adding biplot vectors for vegetation variables to the ordination plots. Coordinates of each vector's terminal point were defined by Pearson's correlations between the values of the variable and the $x$ and $y$ ordination scores at each site. Only statistically significant $(P \leq 0.05)$ vegetation variables were included, as determined by multiple regression using PopTools (Hood 2007), with their significance levels calculated using randomisation tests.

\section{RESULTS}

In total, 14,527 individual ants from 47 genera were collected: 9,904 individuals from 39 genera at 54 sites in the subtropics, and 4,623 individuals from 35 genera at 50 sites in the tropics. Two genera (Pheidole and Rhytidoponera) were present at almost all sites in both regions (96 and 100\% of subtropical sites and 94 and 96\% of tropical sites, respectively: Table 1), and dominated the assemblages numerically (2014 and 5352 individuals respectively in the subtropics; 1636 and 2140 in the tropics). Other common and widespread genera were Paratrechina and Solenopsis (present at 61 and 52\% of subtropical sites and 64 and $36 \%$ of tropical sites, respectively: Table 1). Iridomyrmex 
was present at $28 \%$ of subtropical and $12 \%$ of tropical sites. The other genera were more sparsely distributed.

\section{Genera which discriminated between pasture and rainforest}

The IndVal procedure was used to identify taxa which showed a strong discrimination between the pasture and rainforest reference conditions (not considering the other site-types). Paratrechina had the highest indicator value in both regions (IndVal=89 in subtropics; 90 in tropics; $P<0.001$ in both cases), and was associated with pasture. Other pasture indicators were Aphaenogaster and Solenopsis in the tropics (IndVal $=60, P=0.019$; and IndVal $=55 ; P=0.033$ respectively), and Rhytidoponer and Tetramorium in the subtropics (IndVal $=68, P=0.008$; and IndVal $=60 ; P=0.021$ respectively). There was only one potential rainforest indicator genus in the tropics (Pheidole; IndVal $=67 ; P=0.022$ ), and none in the subtropics.

The frequencies of these species in reforested site-types were generally intermediate between their frequencies in pasture and rainforest (Fig. 1). Paratrechina was less frequent in ER, OP and F site-types than P in both regions; with lower values also for YP in the tropics and RG in the subtropics. In the tropics, Solenopsis showed a similar pattern to Paratrechina. In the subtropics, Rhytidoponera was about half as frequent within $\mathrm{F}$ as in $\mathrm{P}$ sites, but showed similar frequencies to $\mathrm{P}$ across all reforestation treatments. Aphaenogaster in the tropics, and Tetramorium in the subtropics, differed

significantly between $\mathrm{P}$ and $\mathrm{F}$ sites, but were infrequent and highly variable across the whole data sets (Fig. 1). The sole rainforest indicator, Pheidole in the tropics, was recorded at greatest frequencies in $\mathrm{CT}$ and $\mathrm{F}$ sites, was intermediate at $\mathrm{RG}$ and $\mathrm{OP}$ sites, and lowest in frequency at P, YP and ER sites (Fig. 1) . 


\section{Patterns in functional groups}

Dominant Dolichoderinae were mainly Iridomyrmex with a few Anonychomyrma (Table 1), and comprised only a very small percentage of ants overall in both regions (Fig. 2). Opportunists included eight genera, all of which occurred in both regions (Table 1). Opportunists had greatest proportional frequency in $\mathrm{P}$ sites and lowest in $\mathrm{F}$, in both regions, and their frequencies in reforested sites tended to be intermediate (Fig. 2). Generalised Myrmicinae (mainly Pheidole, with some Crematogaster in the subtropics; Table 1) had greatest proportional frequency in F sites in both the tropics and the subtropics (Fig. 2). In the tropics, the frequency of Generalised Myrmicinae in reforested site-types was intermediate between F and P sites, whereas in the subtropics it was similar across pasture and all reforested site-types. In both regions F sites tended to contain a combination of more Generalised Myrmicinae and fewer Opportunists, whereas both P and reforested sites had fewer Generalised Myrmicinae and more Opportunists (Fig. 3). Specialist Predators (with eight genera: Table 1) had greater proportional frequencies in F than P sites in both regions (Fig. 2). Cryptic Species (with 10 genera) occurred relatively uniformly across all site-types in both regions (Fig. 2). Other functional groups occurred sparsely (Table 1).

\section{Multivariate discrimination by genera and functional groups}

Ordinations based on frequencies within both genera and functional groups clearly separated F from P sites in both the tropics and subtropics (Fig. 4). In the tropics, there were gradients in ordination space from $\mathrm{P}$ to $\mathrm{F}$ sites at both genus and functional group levels, associated with increasing canopy cover, tree basal area and leaf litter, and decreasing grass cover. Ordinations of both genera and functional groups placed OP and ER sites closest to F sites, RG sites overlapped the P sites, and YP and CT sites were 
variable or intermediate. Pairwise comparisons of site-types using ANOSIM (Table 2) showed that rainforest (F) sites differed from all other site-types except old plantations $(\mathrm{OP})$, while pasture $(\mathrm{P})$ differed from site-types with the best-developed vegetation (F, OP, ER), but not from the other reforested site-types (except for genera in YP sites). There were few differences among RG, YP and CT sites.

In the subtropics, the gradient between $\mathrm{P}$ and $\mathrm{F}$ in ordination space was less clear, although ER and OP were again most similar to F, with RG sites (comprised of trees in this region) also nearby (Fig. 4). CT sites overlapped the P sites, and YP sites were variable. ANOSIM comparisons showed that $\mathrm{F}$ and $\mathrm{OP}$ differed significantly from all other site-types, except for functional groups in RG (Table 2). P sites also differed from ER for genera, and RG for functional groups, but not from other reforested site-types. There were, again, few differences among RG, YP, and CT sites.

\section{DISCUSSION}

In the present study, there were large overlaps between the ground-active ant genera of rainforest and pasture, particularly in the subtropics, in spite of great differences in above-ground vegetation structure and botanical composition. Ant assemblages in both regions and all site-types were strongly dominated by Pheidole and Rhytidoponera, and less so by Paratrechina, and discrimination between treatments in multivariate analyses was based mainly on variations in the relative frequencies of these genera, rather than the association of genera with particular site-types.

Comparing rainforest with pasture reference sites, we found only one genus (Pheidole) to be potentially indicative of rainforest conditions, and this was only in the tropics. Rainforest indicators may have been scarce because few genera occurred 
consistently across sites within reference site-types, and those that did tended to be ubiquitous across pasture and rainforest. More comprehensive sampling (e.g., extracting ants from leaf litter, collecting aboreal ants) may have revealed more taxa that occurred consistently in rainforest. For example, in the study by King et al. (1998), most ant taxa associated with rainforest were obtained from extracting leaf litter, rather than pitfall traps. However, in the subtropics, Nakamura et al. (2003) were unable to distinguish pasture from rainforest sites using litter-extracted ant genera. Alternatively, had our sites been restricted to a narrower range of environmental conditions, especially in the subtropics where sites varied considerably in rainfall and soil type, we may have found more genera occurring consistently across rainforest sites. For example, Nakamura et al. (2007), working in a small part of our subtropical study region, found several rainforest indicator ant genera with a similar level of sampling effort. However, a restricted relevance to a narrowly-defined environmental context would preclude the use of ant genera as broadly-applicable indicators of ecological change in rainforest landscapes.

Several genera in each region were indicative of pasture conditions. Paratrechina was the only genus which was a pasture indicator in both regions and showed similar patterns in each, decreasing in frequency across the site-types with increasing complexity of woody vegetation. Paratrechina was also indicative of pasture when compared with rainforest in another south east Queensland study (Nakamura et al. 2007), and several other studies have found that Paratrechina responds positively to disturbance (Hoffmann \& Andersen 2003). However, 'pasture indicators' are of limited value in assessing reforestation success because they can only indicate movement of sites away from a pasture-like state, but do not guarantee movement towards a rainforest-like state. For example, young monoculture plantations in the tropics had low 
frequencies of Paratrechina in spite of great differences from rainforest reference sites in vegetation composition and structure (Kanowski et al. 2003; Wardell-Johnson et al. 2005), beetles (Grimbacher et al. 2007) and vertebrate fauna (Catterall et al. 2004; Kanowski et al. 2005, 2006).

Our data provided limited support for the application of the functional group model to assessing rainforest restoration. Three functional groups were considered by Andersen (1995b) as being most important in assessing stress and disturbance: 'Dominant Dolichoderinae' (considered to be aggressive and strongly competitive, highly abundant in hot and open habitats, but often absent from well-shaded habitats); 'Generalised Myrmicinae' (considered to be relatively stress-tolerant, and often dominant in the absence of Dominant Dolichoderines) and 'Opportunists' (considered to be poor competitors and to be ruderal species characteristic of disturbed sites). In the context of reforestation on cleared land, the functional group model would predict that highly-competitive Dominant Dolichoderines would be most common in open habitats created by canopy clearance, whereas Generalised Myrmicinae would dominate shaded habitats. Opportunists are expected to increase in relation to disturbance (King et al. 1998; Andersen 2000). Two other functional groups, Specialist Predators and Cryptic Species, were considered to have highly specialised requirements and negative responses to disturbance (Hoffmann \& Andersen 2003).

Dominant Dolichoderinae were uncommon in this study, and did not dominate structurally more open habitats such as pasture sites, as the functional group model would predict. Perhaps, from the point of view of an epigaeic ant, rainforest and mesic pastures may not be very dissimilar environments. In these pastures, depending on 
stocking rates and season, dense grass can completely shade the soil, effectively providing a 'canopy' cover close to ground level.

However, the functional group model was supported by the observation that ant assemblages in the pasture reference sites tended to comprise relatively high proportions of Opportunists and low proportions of Generalised Myrmicinae, whereas assemblages of the rainforest reference sites showed the opposite pattern. Our results suggest that increases in the ratio of Generalised Myrmicinae to Opportunists may be useful as an operational indicator of the attainment of a rainforest-like state. We found support for the functional group model also in the responses of Specialist Predators. Cryptic Species did not show any particular pattern amongst our site-types, although in Australian rainforests, this group may be poorly sampled by pitfall traps (King et al. 1998).

In both regions, differences between sites in ant assemblage composition were associated with differences in canopy cover, tree basal area, litter and grass cover; i.e., a gradient in structure from pasture to closed forest. The gradient in canopy cover may be especially important, although our data do not allow its effect to be separated from that of the other structural or correlated floristic variables. At their current ages and levels of development, all types of reforestation were clearly different in ant assemblage composition from rainforest reference sites. The sites with assemblages most like those of rainforest were the older monoculture plantations, particularly in the tropics where an understorey of rainforest species had been allowed to develop (Kanowski et al. 2003). While corresponding with the development of a more rainforest-like vegetation structure, the more rainforest-like ant assemblages at the tropical OP sites could also have been affected by previous land use and landscape context, since those sites had generally been established immediately after clearing, without an intervening pasture 
phase, and were mostly immediately adjacent to intact rainforest. The direct conversion of forest to plantation would have provided less opportunity for invasion by opencountry ants, and would also have allowed rainforest ants to persist rather than having to recolonise from elsewhere.

In conclusion, our results indicate that rapid surveys of ground-active ant genera by pitfall-trapping in Australian rainforest landscapes can discriminate between pasture and rainforest sites, but have limited ability to discriminate between different types of reforestation. It is possible that ant responses to the different forms of reforestation would have been more informative at the level of species, but such identification would require more effort and resources than are typically available in rapid assessments.

\section{ACKNOWLEDGEMENTS}

Funding for the project was provided by the Marine and Tropical Sciences Research Facility (through the Reef and Rainforest Research Centre) and the Rainforest Cooperative Research Centre. We thank Grant Wardell-Johnson and Nigel Tucker for their contribution to the project inception and design, Rob Kooyman and Stephen McKenna with help with the vegetation surveys, Terry Reis for help in the field, Annette Ritchie and Monique Shayne for the initial sorting of invertebrates, and Aki Nakamura and Chris Burwell for rechecking and correcting generic (and some species) identifications. Comments on an earlier draft by Peter Grimbacher and referees have improved the manuscript. This work was conducted under the following permits: Griffith University Ethics Committee AES/07/00/aec; Qld. Parks \& Wildlife Service Scientific Purposes Permit F1/000365/00/SAA; Qld Dept. of Natural Resources Permits to Collect 1564, 1613; NSW National Parks \& Wildlife Service Scientific Investigation 
Licence A2877; State Forests of NSW Special Purposes Permit 05553. This paper is dedicated to the memory of our co-author and friend Scott Piper. 


\section{REFERENCES}

Adam P. (1994) Australian Rainforests. Oxford University Press, Oxford.

Agosti D. \& Alonso L. E. (2000) The ALL protocol: a standard protocol for the collection of ground-dwelling ants. In: Ants: Standard Methods for Measuring and Monitoring Biodiversity (eds D. Agosti, J. D. Majer, L. E. Alonso \& T. R. Schultz) pp 204-6. Smithsonian Institution, Washington D.C.

Andersen A. N. (1990) The use of ant communities to evaluate change in Australian terrestrial ecosystems: a review and a recipe. Proc. Ecol. Soc. Aust. 16, 347-57.

Andersen A. N. (1995a) Measuring more of biodiversity: genus richness as a surrogate for species richness in Australian ant faunas. Biol. Conserv. 73, 39-43.

Andersen A. N. (1995b) A classification of Australian ant communities, based on functional groups which parallel plant life-forms in relation to stress and disturbance. J. Biogeogr. 22, 15-29.

Andersen A. N. (1997) Functional groups and patterns of organisation in North American ant communities: a comparison with Australia. J. Biogeogr. 24, 433-60.

Andersen A. N. (2000) A global ecology of rainforest ants: functional groups in relation to environmental stress and disturbance. In: Ants: Standard Methods for Measuring and Monitoring Biodiversity (eds D. Agosti, J. D. Majer, L. E. Alonso \& T. R. Schultz) pp 25-34. Smithsonian Institution, Washington D.C.

Andersen A. N. \& Majer J. D. (2004) Ants show the way Down Under: invertebrates as bioindicators in land management. Front. Ecol. Environ. 2, 291-8. 
Andersen A. N., Hoffmann B. D., Muller W. J. \& Griffiths A. D. (2002) Using ants as bioindicators in land management: simplifying assessment of ant community responses. J. App. Ecol. 39, 8-17.

Ashton M. S., Gunatilleke C. V. Singhakumara B. M. \& Gunatilleke I. A. (2001) Restoration pathways for rainforest in southwest Sri Lanka: a review of concepts and models. For. Ecol. Manage. 154, 409-30.

Bailey R. C., Norris R. H. \& Reynoldson T. B. (2001) Taxonomic resolution of benthic macroinvertebrate communities in bioassessments. J-NABS 20, 280-6.

Balmford A., Green M. J. B. \& Murray M. G. (1996) Using higher-taxon richness as a surrogate for species richness. I. Regional tests. Proc. R. Soc. B. 263, 1267-74.

Blank S., Seiter C. \& Bruce P. (2001) Resampling Stats in Excel, Version 2. Resampling Stats Inc., Arlington.

Block W. M., Franklin A. B., Ward J. P. Jr., Ganey J. L. \& White G. C. (2001) Design and implementation of monitoring studies to elucidate the success of ecological restoration on wildlife. Restor. Ecol. 9, 293-303.

Brown K. S. (1997) Diversity, disturbance, and sustainable use of Neotropical forests: insects as indicators for conservation monitoring. J. Insect Conserv. 1, 25-42.

Brown K. S. (2000) Diversity of ants. In: Ants: Standard Methods for Measuring and Monitoring Biodiversity (eds D. Agosti, J. D. Majer, L. E. Alonso \& T. R. Schultz) pp 45-79. Smithsonian Institution, Washington D.C.

Cagnolo L., Molina S. I, \& Valladares G. R. (2002) Diversity and guild structure of insect assemblages under grazing and exclusion regimes in a montane grassland from Central Argentina. Biodivers. Conserv. 11, 407-20. 
Catterall C. P., Kanowski J., Wardell-Johnson G. W., Proctor H., Reis T., Harrison D. \& Tucker N. I. J. (2004) Quantifying the biodiversity values of restoration:

perspectives, design issues and outcomes in Australian rainforest landscapes. In: Conservation of Australia's Forest Fauna, Volume 2 (ed. D. Lunney), pp. 359-93. Royal Zoological Society of New South Wales, Sydney.

Catterall C. P., Kanowski J. \& Wardell-Johnson G. W. (2008) Biodiversity and new forests: interacting processes, prospects and pitfalls of rainforest restoration. In: Living in a Dynamic Tropical Forest Landscape (eds N. Stork \& S. Turton), pp. 51025. Wiley-Blackwell, Oxford.

Chazdon R. L. (2003) Tropical forest recovery: legacies of human impact and natural disturbances. Perspect. Plant Ecol. Evol. Syst. 6, 51-71.

Clarke K. R. \& Green R. H. (1988) Statistical design and analysis for a 'biological effects' study. Mar. Ecol. Prog. Ser. 46, 213-26.

Clarke K. R. \& Warwick R. M. (2001) Changes in Marine Communities: An Approach to Statistical Analysis and Interpretation. PRIMER-E Ltd., Plymouth.

Dufrene M. and Legendre P. (1997) Species assemblages and indicator species: the need for a flexible asymmetrical approach. Ecol. Monogr. 67, 345-66.

Edgington E. S. (1980) Randomization Tests. Marcel Dekker, New York.

Erskine P. D., Catterall C. P., Lamb D. \& Kanowski J. (2007) Patterns and processes of old field reforestation in Australian rainforest landscapes. In: Old Fields: Dynamics and Restoration of Abandoned Farmland (eds V. A. Cramer \& R. J. Hobbs) pp. $163-$ 94. Island Press, Washington D.C. 
Folgarait P. J. (1998) Ant biodiversity and its relationship to ecosystem functioning: a review. Biodivers. Conserv. 7, 1221-44.

Freudenberger D. \& Harvey J. (2003) Assessing the Benefits of Vegetation Enhancement for Biodiversity: A Framework. Report for Environment Australia. URL http://www.ea.gov.au [accessed on 23 May 2008]

Gaston K. J. \& Williams P. H. (1993) Mapping the world's species - the higher taxon approach. Biodivers. Lett. 1, 2-8.

Grimbacher P. S., Catterall C. P., Kanowski J. \& Proctor H. P. (2007) Responses of ground-active beetle assemblages to different styles of reforestation on cleared rainforest land. Biodivers. Conserv. 16, 2167-84.

Grimbacher P. S., Catterall C. P. \& Kitching R. L. (2008) Detecting the effects of environmental change above the species level with beetles in a fragmented tropical rainforest landscape. Ecol. Entomol. 33, 66-79.

Hoffmann B. D. \& Andersen A. N. (2003) Responses of ants to disturbance in Australia, with particular reference to functional groups. Aust. Ecol. 28, 444-64.

Hood G. M. (2007) Pop Tools version 2.7.5. URL http://www.cse.csiro.au/poptools [accessed on 3 May 2007]

Kanowski J., Catterall C. P. \& Harrison D. A. (2008) Monitoring the outcomes of reforestation for biodiversity conservation. In: Living in a Dynamic Tropical Forest Landscape (eds N. Stork \& S. Turton), pp. 526-36. Wiley-Blackwell, Oxford.

Kanowski J., Catterall C. P., Proctor H., Reis T., Tucker N. I. J. \& Wardell-Johnson G. W. (2005) Biodiversity values of timber plantations and restoration plantings for rainforest fauna in tropical and subtropical Australia. In: Reforestation in the Tropics 
and Subtropics of Australia Using Rainforest Tree Species (eds P. D. Erskine, D. Lamb \& M. Bristow) pp. 183-205. RIRDC, Canberra and Rainforest CRC, Cairns.

Kanowski J., Catterall C. P., Wardell-Johnson G. W., Proctor H. \& Reis T. (2003) Development of forest structure on cleared rainforest land in eastern Australia under different styles of reforestation. For. Ecol. Manage. 183, 265-80.

Kanowski J., Reis T., Catterall C. P. \& Piper S.D. (2006) Factors affecting the use of reforested sites by reptiles in cleared rainforest landscapes in tropical and subtropical Australia. Restor. Ecol. 14, 67-76.

Kaspari M. (2000) A primer on ant ecology. In: Ants: Standard Methods for Measuring and Monitoring Biodiversity (eds D. Agosti, J. D. Majer, L. E. Alonso \& T. R. Schultz) pp 9-24. Smithsonian Institution, Washington D.C.

King J. R., Andersen A. N. \& Cutter A. D. (1998) Ants as bioindicators of habitat disturbance: validation of the functional group model for Australia's humid tropics. Biodivers. Conserv. 7, 1627-38.

Kitching R. L., Bickel D., Creagh A. C., Hurley K. \& Symonds C. (2004) The biodiversity of Diptera in Old World rain forest surveys: a comparative faunistic analysis J. Biogeog. 31, 1185-200

Krell F. (2004) Parataxonomy vs. taxonomy in biodiversity studies - pitfalls and applicability of 'morphospecies' sorting. Biodivers. Conserv. 13, 795-812.

Lamb D., Erskine P. D. \& Parrotta J. A. (2005) Restoration of degraded tropical forest landscapes. Science 310, 1628-32.

Lawton J. H., Bignell D. E., Bolton B., Bloemers G. F., Eggleton P., Hammond P. M., Hodda M., Holt R. D., Larsen T. B., Mawdsley N. A., Stork N. E., Srivastava D. S. 
\& Watt A. D. (1998) Biodiversity inventories, indicator taxa and effects of habitat modification in tropical forest. Nature 391, 7-76.

Lindenmayer D. B., Margules C. R. \& Botkin D. B. (1999) Indicators of biodiversity for ecologically sustainable forest management. Conserv. Biol. 14, 941-50.

Longino J. T., Coddington J. \& Colwell R. K. (2002) The ant fauna of a tropical rain forest: estimating species richness three different ways. Ecology 83, 689-702.

Lugo A. E. \& Helmer E. (2004) Emerging forests on abandoned land: Puerto Rico's new forests. For. Ecol. Manage. 190, 145-61.

Majer J. D. (1983) Ants: bio-indicators of minesite rehabilitation, land-use and land conservation. Environ. Manage. 7, 375-83.

Major R. E., Smith D., Cassis G., Gray M. \& Colgan D. J. (1999) Are roadside strips important reservoirs of invertebrate diversity? A comparison of the ant and beetle faunas of roadside strips and large remnant woodlands. Aust. J. Zool. 47, 611-24.

McGeogh M. A. (1998) The selection, testing and application of terrestrial insects as bioindicators. Biol. Rev. 73, 181-201.

Nakamura A., Proctor H. \& Catterall C. P. (2003) Using soil and litter arthropods to assess the state of rainforest restoration. Ecol. Manage. Restor. 4, S20-8.

Nakamura A., Catterall C. P., House A. P. N., Kitching R. L. \& Burwell C. J. (2007) The use of ants and other soil and litter arthropods as bio-indicators of the impacts of rainforest clearing and subsequent land use. J. Insect Conserv. 11, 177-86. 
Nakamura A., Catterall C. P., Kitching R. L., House A. P. N. \& Burwell C. J. (2008) Effects of isolation on the colonisation of restored habitat patches by forestdependent arthropods of soil and litter. Insect Conserv. Divers. 1, 9-21.

Neilan W., Catterall C. P., Kanowski J. \& McKenna S. (2006) Do frugivorous birds assist rainforest succession in weed dominated oldfield regrowth of subtropical Australia? Biol. Conserv. 129, 393-407.

Neville P. J. \& New T. R. (1999) Ant genus to species ratios: a practical trial for surrogacy value in Victorian forests. In: The Other 99\%. The Conservation and Biodiversity of Invertebrates. (eds W. Ponder \& D. Lunney) pp. 133-7. Royal Zoological Society of New South Wales, Sydney.

New T. R. (2000) How useful are ant assemblages for monitoring habitat disturbance on grasslands in south eastern Australia? J. Insect Conserv. 4, 153-9.

Parrotta J. A., Turnbull J. W. \& Jones N. (1997). Catalyzing native forest regeneration on degraded tropical lands. For. Ecol. Manage. 99, 1-7.

Pik A. J., Oliver I. \& Beattie A. J. (1999) Taxonomic sufficiency in ecological studies of terrestrial invertebrates. Aust. J. Ecol. 24, 555-62.

Pik A. J., Dangerfield J. M., Bramble R. A., Angus C. \& Nipperess D. A. (2002) The use of invertebrates to detect small-scale habitat heterogeneity and its application to restoration practices. Environ. Monit. Assess. 75, 179-99.

Schnell M. R., Pik A. J. \& Dangerfield J. M. (2003) Ant community succession within eucalypt plantations on used pasture and implications for taxonomic sufficiency in biomonitoring. Aust. Ecol. 28, 553-65. 
Shattuck S. O. \& Barnett N. J. (2001) Australian Ants Online: Guide to the Australian Ant Fauna. URL http://www.ento.csiro.au/science/ants/default.htm [accessed on 2 March 2005]

Soares S. M. \& Schoereder J. H. (2001) Ant-nest distribution in a remnant of tropical rainforest in southeastern Brazil. Insectes Soc. 48, 280-86.

Ward D. F. \& Lariviere M. (2004) Terrestrial invertebrate surveys and rapid biodiversity assessment in New Zealand: lessons from Australia. New Zeal J. Ecol. 28, 151-9.

Wardell-Johnson G. W., Kanowski J., Catterall C. P., McKenna S., Piper S. \& Lamb D. (2005) Rainforest timber plantations and the restoration of plant biodiversity in tropical and subtropical Australia. In: Reforestation in the Tropics and Subtropics of Australia Using Rainforest Tree Species (eds P. D. Erskine, D. Lamb \& M. Bristow) pp. 162-82. RIRDC, Canberra and Rainforest CRC, Cairns.

Williams P. H. \& Gaston K. J. (1994) Measuring more of biodiversity: can higher taxon richness predict wholesale species richness? Biol. Conserv. 67, 211-7.

Wilson E. O. (1958) Patchy distribution of ant species in New Guinea rain forests. Psyche 65, 26-38.

Wilson E. O. (1990) Success and Dominance in Ecosystems: The Case of Social Insects. Ecology Institute, Oldendorf/Luhe, Germany. 
Table 1. Epigeic ant genera recorded from pitfall traps in reforested, pasture and rainforest reference sites in tropical and subtropical Australia.. Data are the number of sites in which each genus was recorded by site type and region.

\begin{tabular}{|c|c|c|c|c|c|c|c|c|c|c|c|c|c|c|c|}
\hline \multirow[t]{3}{*}{ Subfamily } & \multirow{3}{*}{$\begin{array}{l}\text { Genera (functional } \\
\text { group) }\end{array}$} & \multicolumn{7}{|c|}{ TROPICS } & \multicolumn{7}{|c|}{ SUBTROPICS } \\
\hline & & \multicolumn{7}{|c|}{ Site types (no. of sites) } & \multicolumn{7}{|c|}{ Site types (no. of sites) } \\
\hline & & $\begin{array}{c}\mathrm{P} \\
(5)\end{array}$ & $\begin{array}{l}\mathrm{RG} \\
(5)\end{array}$ & $\begin{array}{l}\text { YP } \\
(5)\end{array}$ & $\begin{array}{l}\mathrm{CT} \\
(5)\end{array}$ & $\begin{array}{l}\text { ER } \\
(10)\end{array}$ & $\begin{array}{l}\text { OP } \\
(10)\end{array}$ & $\begin{array}{c}\mathrm{F} \\
(10)\end{array}$ & $\begin{array}{c}\mathrm{P} \\
(5)\end{array}$ & $\begin{array}{l}\mathrm{RG} \\
(5)\end{array}$ & $\begin{array}{l}\text { YP } \\
(5)\end{array}$ & $\begin{array}{l}\mathrm{CT} \\
(10)\end{array}$ & $\begin{array}{l}\text { ER } \\
(9)\end{array}$ & $\begin{array}{l}\text { OP } \\
(10)\end{array}$ & $\begin{array}{c}\mathrm{F} \\
(10)\end{array}$ \\
\hline Aenictinae & Aenictus (TCS) & 2 & 1 & & & & & & & & & & & & \\
\hline Cerapachyinae & Cerapachys (SP) & & & & & & & & & & 1 & & & & \\
\hline \multirow{7}{*}{ Dolichoderinae } & Anonychomyrma (DD) & & & & & 1 & & 2 & & & & & 3 & 4 & 1 \\
\hline & Dolichoderus (CCS) & & & & & & & & & & 1 & & & & \\
\hline & Iridomyrmex (DD) & 2 & 1 & & 3 & & & & 3 & 1 & 4 & 4 & 1 & 1 & 1 \\
\hline & Leptomyrmex (TCS) & & & & & & 1 & & & & & 1 & & 4 & \\
\hline & Ochetellus (OPP) & & 1 & & & & & & & & 1 & 1 & & & \\
\hline & Tapinoma (OPP) & 2 & 1 & 1 & & 2 & & & 1 & 1 & 2 & 3 & 1 & 2 & \\
\hline & Technomyrmex (OPP) & & & & & 2 & & & & 1 & & 1 & 1 & & 1 \\
\hline \multirow[t]{5}{*}{ Formicinae } & Camponotus (SC) & & & & & & & & & & & 1 & 2 & 1 & \\
\hline & Notoncus (CCS) & 2 & 1 & & & & & & 2 & 1 & 3 & 2 & 2 & 6 & 5 \\
\hline & Notostigma (SC) & & & & & & & 1 & & & 1 & & & & \\
\hline & Paratrechina (OPP) & 5 & 4 & 2 & 4 & 8 & 4 & 5 & 5 & & 3 & 8 & 4 & 8 & 5 \\
\hline & Polyrhachis (SC) & & & & & 1 & & & & & & & 1 & & 1 \\
\hline Leptanillinae & Leptanilla (CS) & & & & & & & & & & & & & & 1 \\
\hline Myrmeciinae & Myrmecia (SP) & & & & & & & & & & & 1 & 1 & 1 & \\
\hline \multirow[t]{11}{*}{ Myrmicinae } & Anillomyrma (CS) & & & & & & & 4 & & & 1 & & & 1 & \\
\hline & Aphaenogaster (OPP) & 3 & 1 & & 1 & 2 & & & 1 & & 1 & 4 & & 1 & 1 \\
\hline & Cardiocondyla (OPP) & 1 & & 1 & & & & 1 & 1 & & 1 & 1 & & & \\
\hline & Carebara (CS) & 2 & 2 & 1 & 2 & 3 & 4 & & & 2 & & 1 & & 3 & \\
\hline & Colobostruma (SP) & & 1 & & & & & & & & & 2 & & & \\
\hline & Crematogaster (GM) & & & & & & & & 1 & & 2 & 3 & 1 & 3 & 1 \\
\hline & Eurhopalothrix (CS) & & & & & & & & & & & & 1 & & \\
\hline & Mayriella (TCS) & & & & & & & & 1 & & & 2 & 1 & & \\
\hline & Meranoplus (HCS) & & & 1 & & & & & 1 & & & & & 1 & 1 \\
\hline & Mesostruma (SP) & & & & & & & & 1 & & & & & & \\
\hline & Monomorium ${ }^{\dagger}$ & 1 & & & 1 & & & & 1 & & & 1 & & 1 & \\
\hline
\end{tabular}




\begin{tabular}{|c|c|c|c|c|c|c|c|c|c|c|c|c|c|c|c|}
\hline & Myrmecina $^{\dagger}$ & & & 1 & & & & & & & & & & & \\
\hline & Orectognathus (SP) & & 1 & & & & & & & & & & & 1 & \\
\hline & Pheidole (GM) & 4 & 5 & 4 & 5 & 9 & 10 & 10 & 5 & 5 & 5 & 9 & 8 & 10 & 10 \\
\hline & Pheidologeton (CS) & & & 1 & & & & & & & & & & & \\
\hline & Podomyrma ${ }^{\dagger}$ & & & & & & & 1 & & & & & & & \\
\hline & Rhoptromyrmex ${ }^{\dagger}$ & & & & 1 & & & & & & & & & & \\
\hline & Romblonella (TCS) & & & & & & & & & & & & 1 & & \\
\hline & Solenopsis (CS) & 3 & 3 & 2 & 4 & 5 & 1 & 2 & 2 & 4 & 4 & 5 & 4 & 7 & 2 \\
\hline & Strumigenys (CS) & 2 & 2 & 2 & & & & 1 & & 1 & & 2 & 1 & 1 & \\
\hline & Tetramorium (OPP) & 1 & & 1 & 1 & & & & 3 & & 1 & & & 1 & \\
\hline Ponerinae & Amblyopone (CS) & & & & & & & & & 1 & & & & & \\
\hline & Heteroponera (CCS) & & 1 & & 2 & & & & 1 & 1 & 1 & 4 & 2 & 4 & 2 \\
\hline & Hypoponera (CS) & 2 & & & & 1 & 3 & & 1 & & & 4 & 2 & 3 & 4 \\
\hline & Leptogenys (SP) & & & & & & 2 & 3 & 1 & 1 & 1 & 1 & & 7 & 5 \\
\hline & Myopias (CS) & & & 1 & 1 & & & & & & & & & & \\
\hline & Odontomachus $^{\dagger}$ & & & & & & 1 & & & & & & & & \\
\hline & Onychomyrmex (TCS) & & & & & & & 1 & & & & & & & \\
\hline & Pachycondyla (SP) & & 1 & & & & 2 & 3 & 2 & 3 & & 1 & 7 & 8 & 3 \\
\hline & Platyt hyrea (SP) & & & & & & & & & & 1 & & & & \\
\hline & Rhytidoponera (OPP) & 5 & 5 & 5 & 4 & 9 & 9 & 10 & 5 & 5 & 5 & 10 & 9 & 10 & 10 \\
\hline
\end{tabular}

Site-types: $\mathrm{P}=$ pasture, $\mathrm{RG}=$ regrowth, $\mathrm{YP}=$ young monoculture plantation, $\mathrm{CT}=$ mixed species cabinet timber plantation, $\mathrm{ER}=$ ecological restoration planting, $\mathrm{OP}=$ old monoculture plantation, $\mathrm{F}=$ rainforest. Functional groups: Dominant Dolichoderinae (DD), Generalised Myrmicinae (GM), Opportunists (OPP), Specialist Predators (SP), Cryptic Species (CS), Cold Climate Specialists (CCS), Hot Climate Specialists (HCS), Tropical Climate Specialists (TCS), and Subordinate Camponotini (SC). ${ }^{\dagger}=$ genera to which a single functional group could not be attributed. 
Table 2. Composition of epigeic ant genera and functional groups among site-types in the tropics and subtropics, using group and pairwise ANOSIM tests (R statistics and significance are shown).

\begin{tabular}{|c|c|c|c|c|c|c|}
\hline $\begin{array}{l}\text { Site-types } \\
\text { (no. of } \\
\text { sites) }\end{array}$ & $\mathrm{P}(5)$ & RG & YP & $\mathrm{CT}$ & ER & $\mathrm{OP}$ \\
\hline \multicolumn{7}{|c|}{ Tropical genera (Global $\mathrm{R}=0.270, P<0.001)$} \\
\hline $\mathrm{RG}(5)$ & -0.12 & & & & & \\
\hline YP (5) & $0.30^{*}$ & $0.24 *$ & & & & \\
\hline СТ (5) & 0.05 & -0.08 & $0.32 *$ & & & \\
\hline ER (10) & $0.40 * * *$ & 0.24 & -0.04 & 0.18 & & \\
\hline $\mathrm{OP}(10)$ & $0.58 * *$ & $0.46^{* *}$ & 0.11 & $0.42 * *$ & 0.03 & \\
\hline $\mathrm{F}(10)$ & $0.80 * * *$ & $0.60^{* * *}$ & $0.30^{*}$ & $0.45^{* *}$ & $0.22 * *$ & 0.11 \\
\hline \multicolumn{7}{|c|}{ Tropical functional groups (Global $\mathrm{R}=0.184, P<0.001$ ) } \\
\hline $\mathrm{RG}(5)$ & -0.03 & & & & & \\
\hline YP (5) & 0.15 & -0.01 & & & & \\
\hline CT (5) & 0.11 & -0.10 & 0.16 & & & \\
\hline ER (10) & $0.26^{*}$ & 0.14 & -0.07 & 0.14 & & \\
\hline $\mathrm{OP}(10)$ & $0.58 * *$ & $0.29 *$ & 0.02 & $0.30^{*}$ & 0.00 & \\
\hline $\mathrm{F}(10)$ & $0.64 * *$ & $0.38^{*}$ & 0.21 & $0.29 *$ & $0.26^{*}$ & 0.03 \\
\hline \multicolumn{7}{|c|}{ Subtropical genera (Global $\mathrm{R}=0.260, P<0.001)$} \\
\hline RG (5) & 0.18 & & & & & \\
\hline YP (5) & 0.10 & $0.34^{*}$ & & & & \\
\hline СТ (10) & 0.00 & 0.14 & $0.38^{*}$ & & & \\
\hline ER (9) & $0.25^{* * *}$ & -0.09 & $0.33^{*}$ & $0.23^{*}$ & & \\
\hline $\mathrm{OP}(10)$ & $0.53 * *$ & 0.20 & $0.36^{*}$ & $0.52 * * *$ & $0.22^{* *}$ & \\
\hline $\mathrm{F}(10)$ & $0.82 * * *$ & $0.57 * * *$ & $0.49 * *$ & $0.80^{* * *}$ & $0.48^{* * *}$ & $0.19^{*}$ \\
\hline \multicolumn{7}{|c|}{ Subtropical functional groups (Global $\mathrm{R}=0.216, P<0.001)$} \\
\hline $\mathrm{RG}(5)$ & $0.48 * *$ & & & & & \\
\hline YP (5) & -0.03 & $0.40^{*}$ & & & & \\
\hline СТ (10) & -0.13 & 0.06 & 0.15 & & & \\
\hline ER (9) & 0.19 & -0.23 & $0.32 *$ & 0.11 & & \\
\hline $\mathrm{OP}(10)$ & $0.35^{* *}$ & $0.22 *$ & $0.37 * *$ & $0.30 * *$ & 0.14 & \\
\hline $\mathrm{F}(10)$ & $0.46^{* *}$ & 0.19 & $0.34 * *$ & $0.58^{* * *}$ & $0.32 * *$ & $0.28 * *$ \\
\hline
\end{tabular}




\section{FIGURE LEGENDS}

Figure 1. Mean $( \pm \mathrm{SE})$ frequencies of epigeic ant indicator genera across site-types in tropical and subtropical Australia. $P$ values determined by randomisation from Analysis of Variance (d.f. $=6,43$ (tropics), 6, 47 (subtropics)). Different letters indicate means differed significantly in pairwise comparisons. Analyses used log-transformed data; plots show raw data. Site-types: $\mathrm{P}=$ pasture, $\mathrm{RG}=$ regrowth, $\mathrm{YP}=$ young monoculture plantation, $\mathrm{CT}=$ mixed species cabinet timber plantation, $\mathrm{ER}=$ ecological restoration planting, $\mathrm{OP}=$ old monoculture plantation, $\mathrm{F}=$ rainforest.

Figure 2. Mean ( \pm SE) contributions to total epigeic ant frequency of selected functional groups across site-types in tropical and subtropical Australia. $P$ values determined by randomisation from Analysis of Variance (d.f.=6, 43 (tropics), 6, 47 (subtropics)). Different letters indicate that means differed signicantly in pairwise comparisons. Site-types: $\mathrm{P}=$ pasture, $\mathrm{RG}=$ regrowth, $\mathrm{YP}=$ young monoculture plantation, $\mathrm{CT}=$ mixed species cabinet timber plantation, $\mathrm{ER}=$ ecological restoration planting, $\mathrm{OP}=$ old monoculture plantation, $\mathrm{F}=$ rainforest.

Figure 3. Relationship between the proportional contributions of Opportunists and Generalised Myrmicinae to total frequency of epigeic ant functional groups across 50 sites in tropical and 54 sites in subtropical Australia. Site-types: $\mathrm{P}=$ pasture, $\mathrm{RG}=$ regrowth, $\mathrm{YP}=$ young monoculture plantation, $\mathrm{CT}=$ mixed species cabinet timber plantation, $\mathrm{ER}=$ ecological restoration planting, $\mathrm{OP}=$ old monoculture plantation, $\mathrm{F}=$ rainforest.

Figure 4. MDS ordinations of sites in tropical and subtropical Australia on the basis of the frequencies of epigeic ant genera and functional groups.. Stress values for genera were 0.17 for tropics and 0.12 for subtropics; for functional groups, values were 0.15 
for tropics and 0.17 for subtropics. Biplot vectors show the trend in increasing values for vegetation structural variables in relation to the ordination of sites: canopy foliage cover $(\%)$, tree basal area $\left(\mathrm{m}^{2} / \mathrm{ha}\right)$, litter dry weight $(\mathrm{t} / \mathrm{ha})$, and groundcover of grasses (index, 0-25). Site-types: $\mathrm{P}=$ pasture, $\mathrm{RG}=$ regrowth, $\mathrm{YP}=$ young monoculture plantation, $\mathrm{CT}=$ mixed species cabinet timber plantation, $\mathrm{ER}=$ ecological restoration planting, $\mathrm{OP}=$ old monoculture plantation, $\mathrm{F}=$ rainforest. 

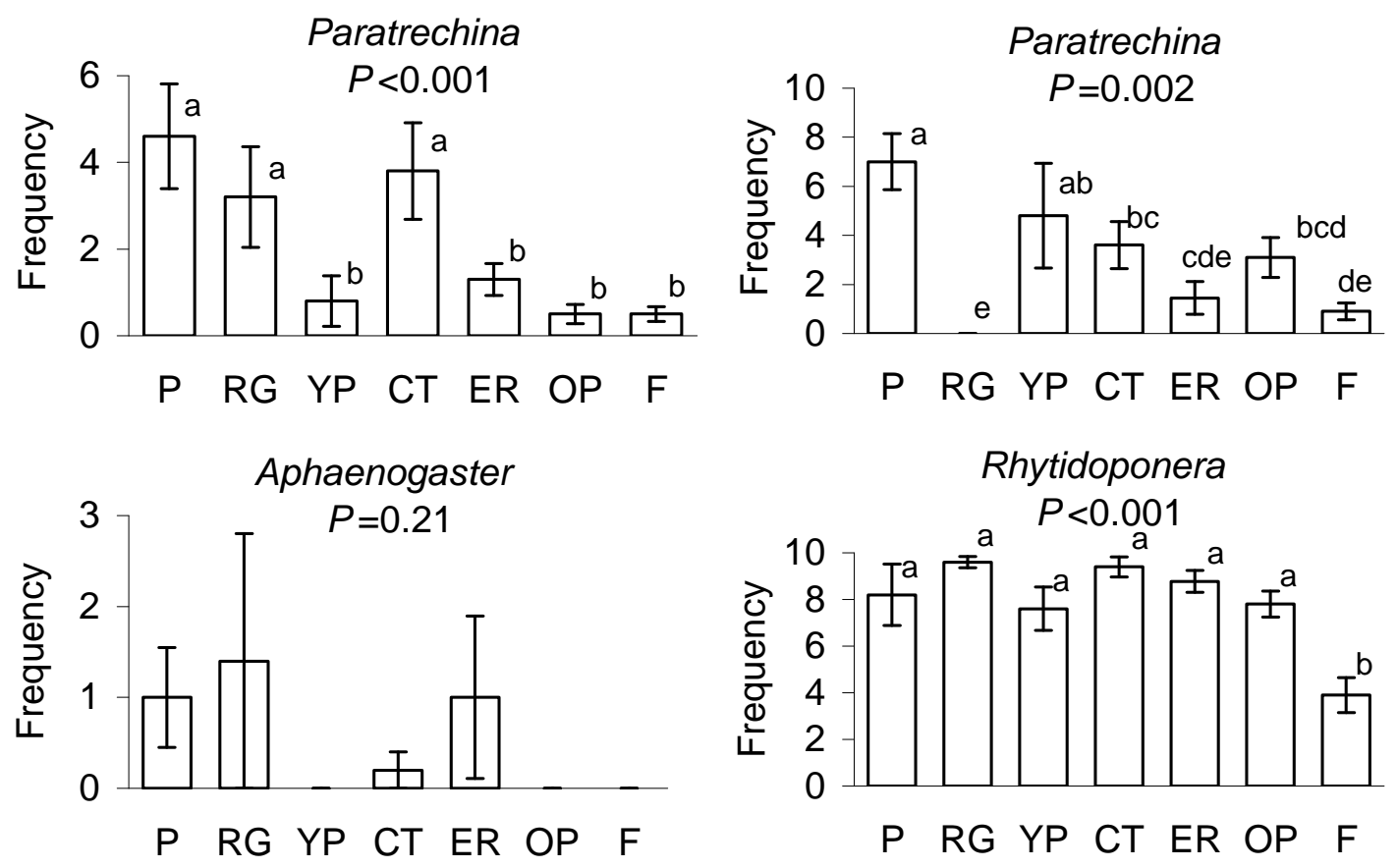

Rhytidoponera
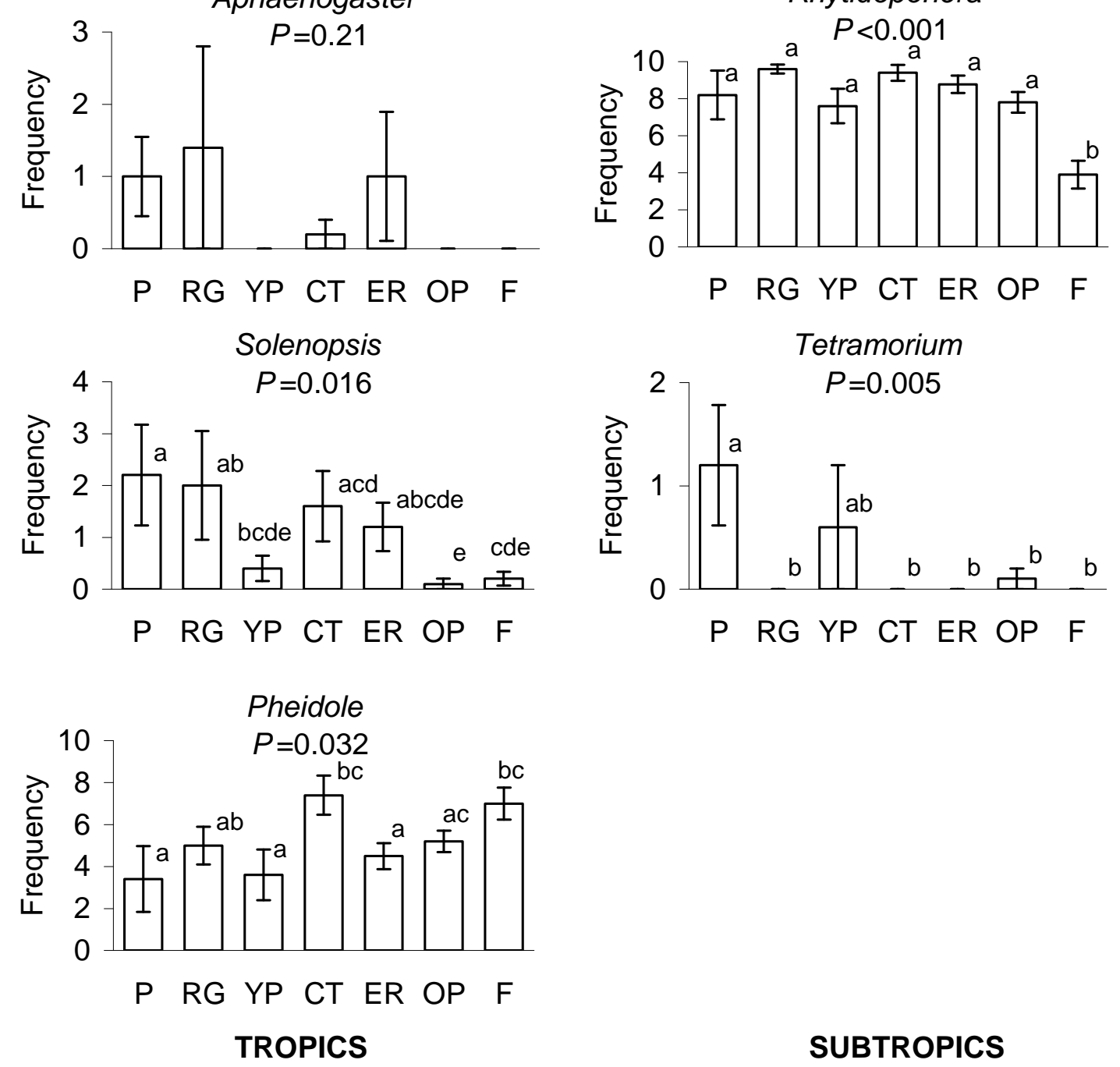

SUBTROPICS

Figure 1 

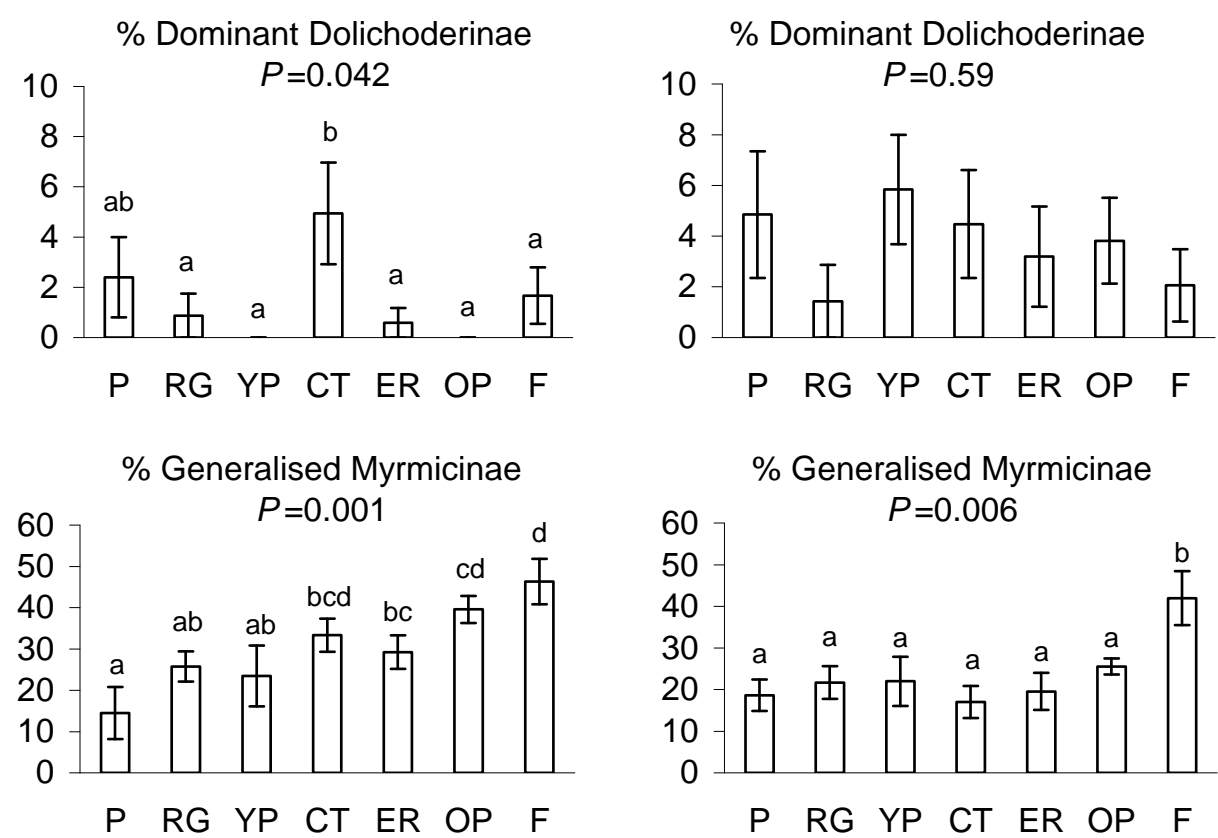

\% Generalised Myrmicinae
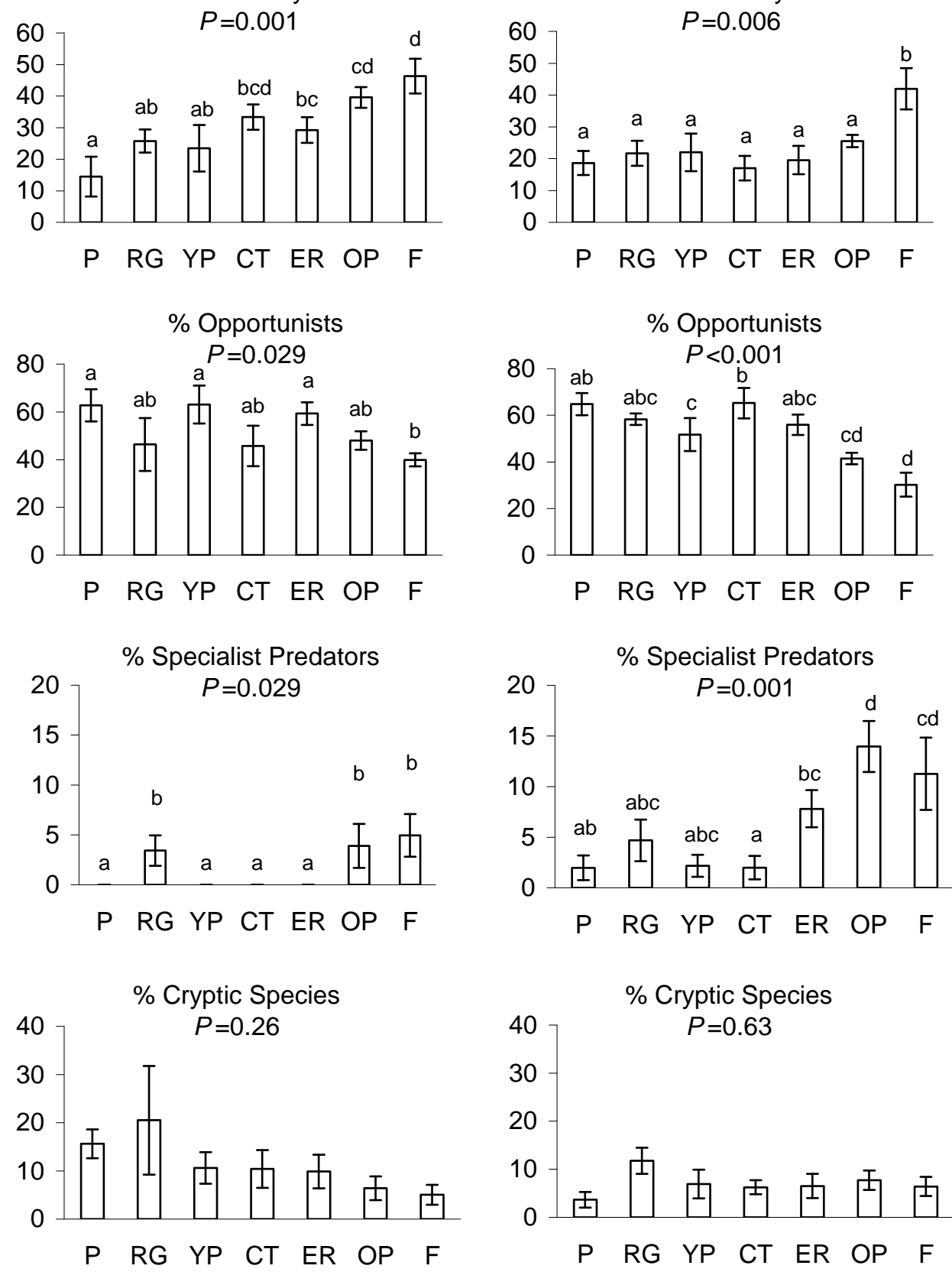

Figure 2

\section{Subtropics}



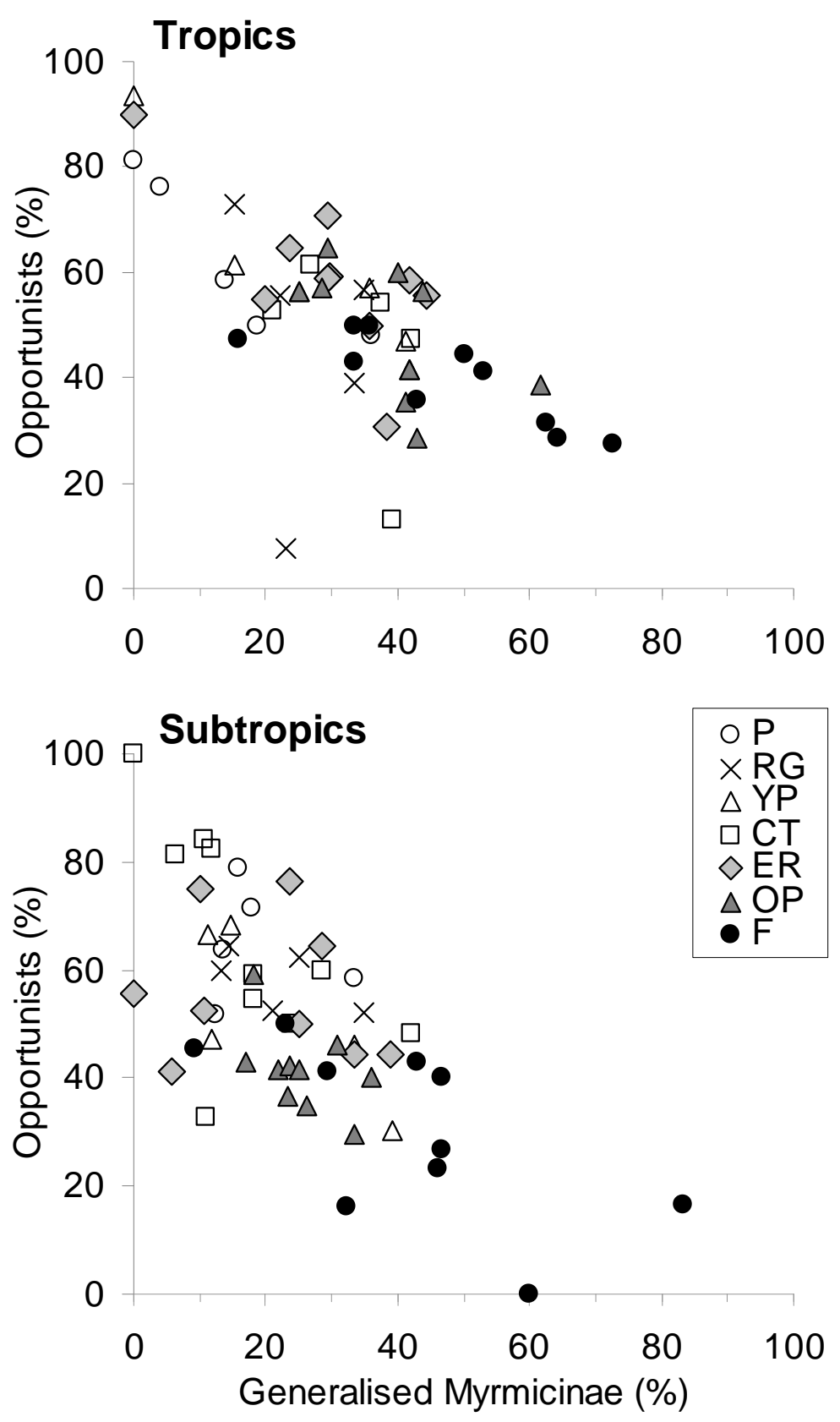

Figure 3 

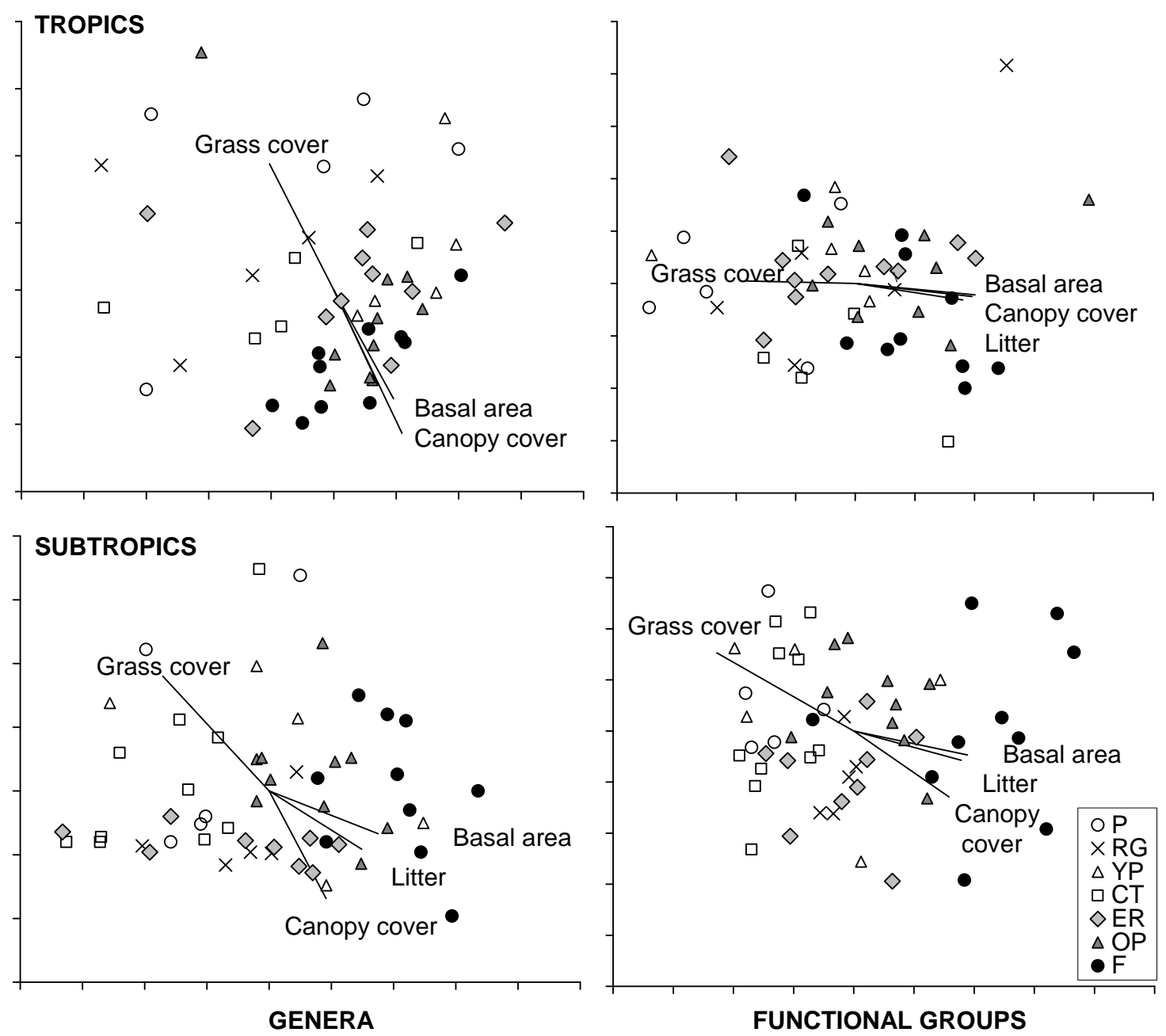

Figure 4 